\title{
From JLP to Crystal: Effects of Solvent on Self-assembly of Cefotaxime Sodium
}

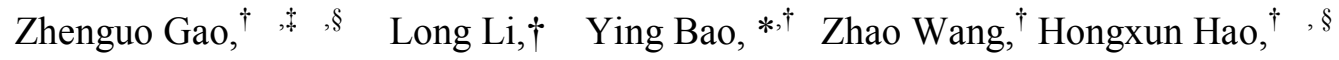

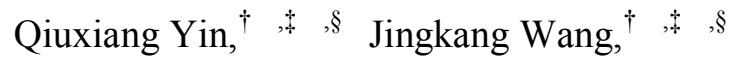

${ }^{\dagger}$ School of Chemical Engineering and Technology, Tianjin University, Tianjin, 300072, P R China

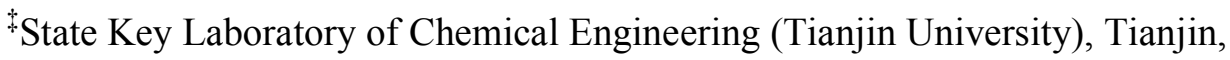
300072, P R China

${ }^{\S}$ Collaborative Innovation Centre of Chemical Science and Engineering (Tianjin), Tianjin, 300072, P R China

\section{Supporting Information:}

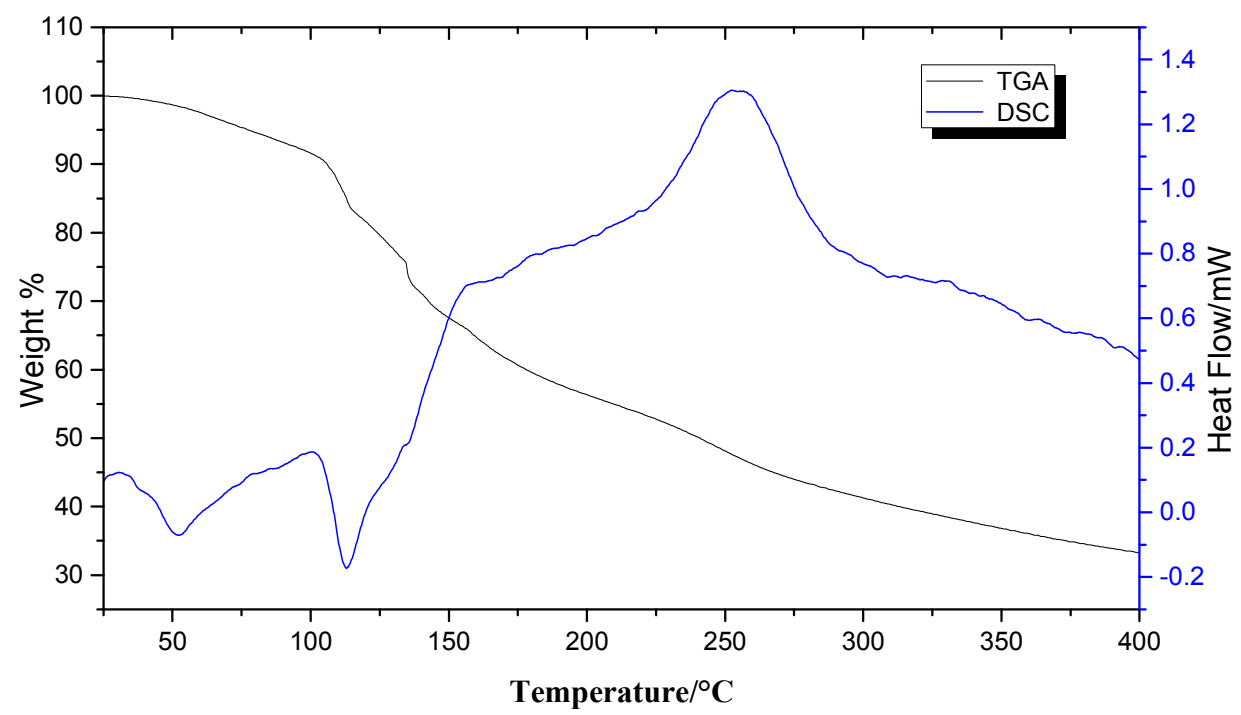

Figure S1 TGA and DSC curves of C2. 


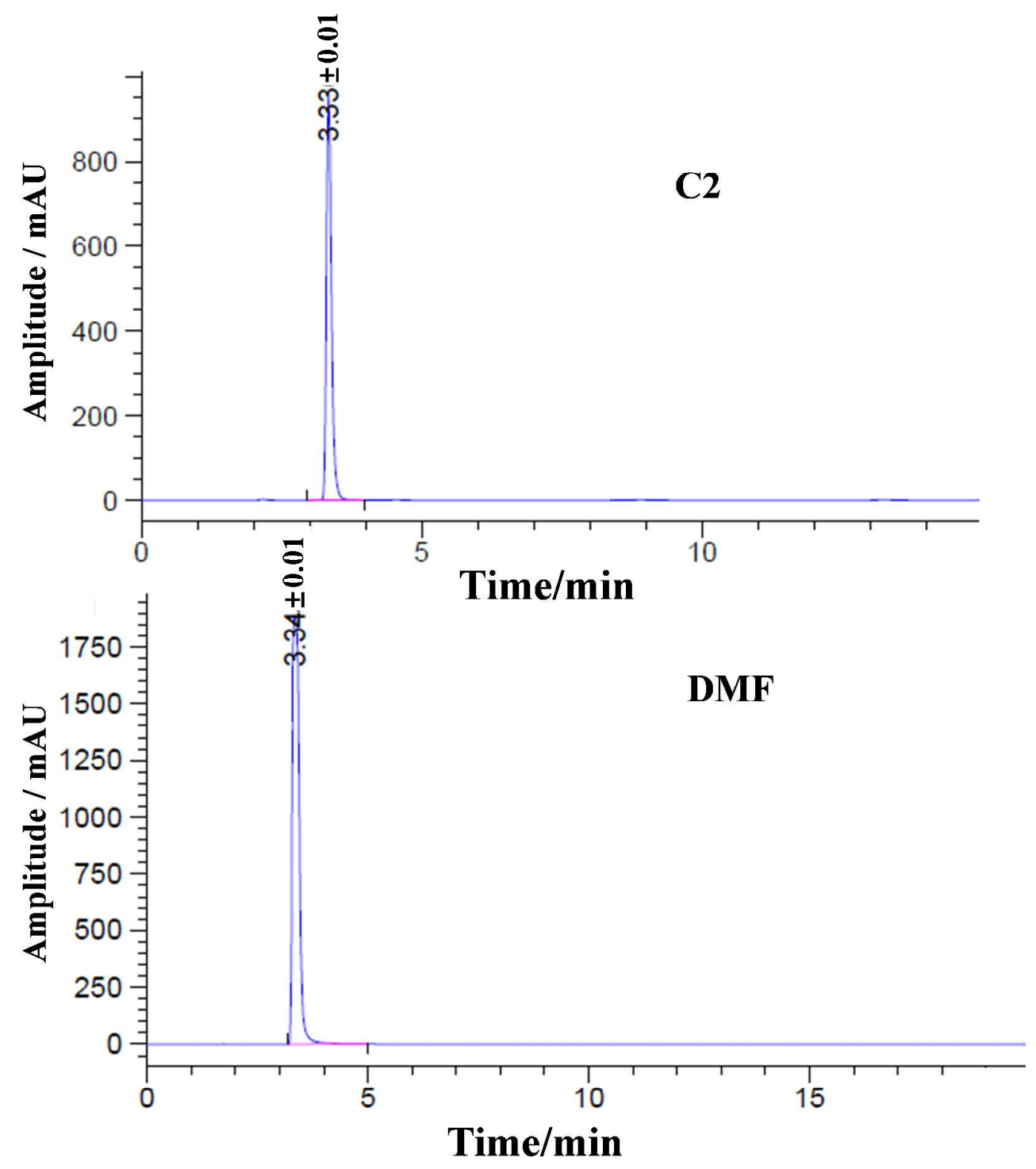

Figure S2 HPLC chromatograms of DMF and C2. (The uncertainty of the time is $0.01 \mathrm{~min}$ ) 

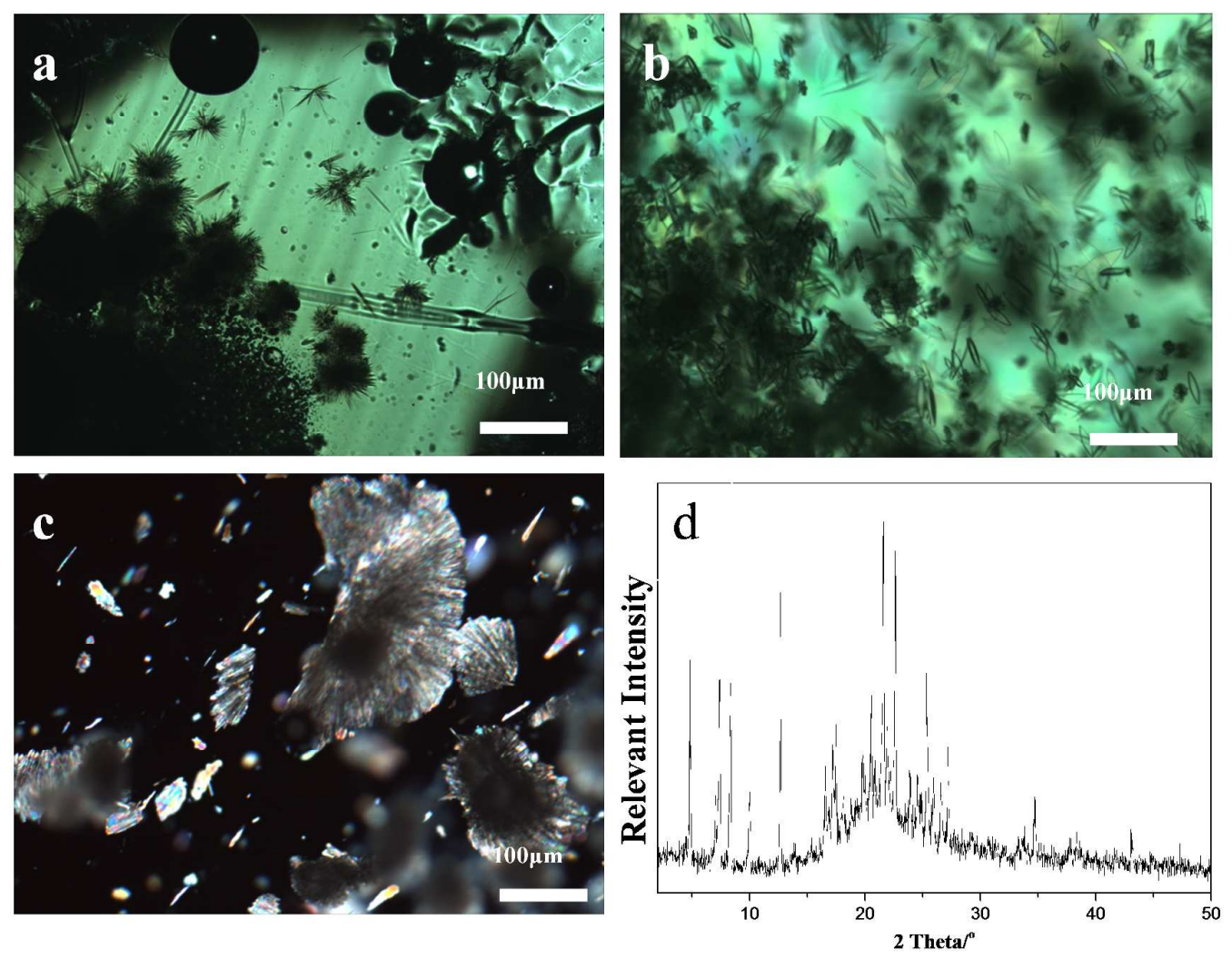

Figure S3 Microscopic images of crystals obtained from JLP crystallization under the atmosphere of (a) formamide, (b) methanol, (c) pyridine. The crystals are (a) needle-like, (b) rod-like and (c) block-like respectively. (d) is XRPD of the crystal crystallized under pyridine atmosphere. It is different from any of the crystals discovered until now. 
Table S1 Observed characteristic peaks of FT-IR and Raman and their assignments for C1.

\begin{tabular}{|c|c|c|}
\hline $\begin{array}{l}\text { Wavenumber } \\
\text { of FT-IR } \\
\left(\mathrm{cm}^{-1}\right)\end{array}$ & $\begin{array}{l}\text { Raman } \\
\text { shift }^{b} \\
\left(\mathrm{~cm}^{-1}\right)\end{array}$ & Assignments \\
\hline 358 & & Hydroxy stretching vibration \\
\hline $3442 / 3342$ & & Primary amine $\mathrm{NH}_{2}$ stretching vibration \\
\hline 3262 & & Secondary amine N-H stretching vibration \\
\hline 3042 & & Aromatic heterocyclic $\mathrm{C}-\mathrm{H}$ chain stretching vibration \\
\hline 1760 & 1752 & $\mathrm{C}=\mathrm{O}$ (in lactam ring) stretching vibration \\
\hline 1728 & & Acetoxyl - $-\mathrm{OCOCH}_{3}$ stretching vibration \\
\hline \multirow[t]{2}{*}{1647} & 1640 & $\mathrm{C}=\mathrm{N}$ stretching vibration in methoxy oxime \\
\hline & 1586 & $\begin{array}{l}\mathrm{C}=\mathrm{C} \quad \text { stretching vibration in five-membered and } \\
\text { six-membered ring }\end{array}$ \\
\hline 1541 & 1531 & Carboxylate radical $\mathrm{COO}^{-}$asymmetric stretching vibration \\
\hline \multirow[t]{5}{*}{$1416 / 1355$} & $1403 / 1355$ & Carboxylate radical $\mathrm{COO}^{-}$symmetric stretching vibration \\
\hline & 817 & Symmetric stretching vibration of thiazine ring \\
\hline & 748 & Lactam ring stretching vibration \\
\hline & 433 & Skeleton bending vibration of Thiazine ring \\
\hline & 274 & $\mathrm{C}-\mathrm{S}-\mathrm{C}$ bending vibration \\
\hline
\end{tabular}

a: The uncertainty of the wavenumber of the characteristic peak was $2 \mathrm{~cm}^{-1}$.

b: The uncertainty of the Raman shift of the characteristic peak was $1 \mathrm{~cm}^{-1}$. 